in vivo $33: 93-98(2019)$

doi:10.21873/invivo.11444

\title{
Suppressive Activity of Adiponectin on the Development of Allergic Rhinitis in Mice
}

\author{
SUGURU FURUKAWA ${ }^{1}$, KAZUHITO ASANO ${ }^{2}$ and HITOME KOBAYASHI ${ }^{1}$ \\ ${ }^{1}$ Department of Otolaryngology, School of Medicine, Showa University, Tokyo, Japan; \\ ${ }^{2}$ Division of Physiology, School of Nursing and Rehabilitation Sciences, Showa University, Yokohama, Japan
}

\begin{abstract}
Background/Aim: Adiponectin is accepted as playing pivotal roles in the development of allergic rhinitis (AR) through modulation of production of inflammatory mediators. Although it is also well known that neuropeptides, especially substance $P(S P)$, function in the development and persistence of clinical conditions of $A R$, the influence of adiponectin on neuropeptide production is not well understood. The present study was designed to examine the influence of adiponectin on the production of SP both in vivo and in vitro. Materials and Methods: PC-12 cells $\left(1 \times 10^{4}\right.$ cells $)$ were stimulated with $10.0 \mathrm{ng} / \mathrm{ml}$ nerve growth factor (NGF) for $2 \mathrm{~h}$ and then with $10.0 \mathrm{ng} / \mathrm{ml}$ capsaicin in the presence of different concentrations of adiponectin. After $72 \mathrm{~h}$, culture supernatants were obtained, and SP levels were measured with enzymelinked immunosorbent assay (ELISA). The influence of adiponectin on the total number of neurites developed per $P C$ 12 cell and on the percentage of $P C-12$ cells with outgrowing neurites was also examined 24 and $72 h$ after the start of culture, respectively. In the second part of the study, BALB/C mice were sensitized intraperitoneally with $1.0 \mu \mathrm{g}$ of ovalbumin and then challenged with intranasal ovalbumin. At 7 days following sensitization, these mice were treated with different doses of adiponectin intranasally in a volume of $5.0 \mu \mathrm{l}$. Nasal allergy-like symptoms, which were induced by bilateral application of $0.1 \%$ OVA $(5.0 \mu \mathrm{l})$, were assessed by counting sneezing and nasal rubbing behavior for $10 \mathrm{~min}$ immediately after nasal ovalbumin challenge. SP levels in nasal lavage fluid obtained 6 h after nasal ovalbumin challenge were examined
\end{abstract}

This article is freely accessible online.

Correspondence: Kazuhito Asano, Division of Physiology, School of Nursing and Rehabilitation Sciences, Showa University, 1865 Touka-Ichiba, Midori-Ku, Yokohama 226-8555, Japan. Tel: +81 459856538, Fax: +81 459857538, e-mail: asanok@med.showau.ac.jp

Key Words: Adiponectin, mouse model, suppression, substance $\mathrm{P}$, nasal allergy-like symptoms. by ELISA. Results: Treatment of NGF-stimulated PC-12 cells with adiponectin suppressed SP production, which was induced by capsaicin stimulation. The minimum concentration of adiponectin that caused significant suppression was $7.5 \mathrm{ng} / \mathrm{ml}$. On the other hand, adiponectin did not affect the total number of neurites and the percentage of PC-12 cells with outgrowing neurites, even at $1,000 \mathrm{ng} / \mathrm{ml}$. Intranasal instillation of adiponectin into ovalbumin-sensitized mice at more than 10.0 $\mathrm{ng} / \mathrm{ml}$, but not $5.0 \mathrm{ng} / \mathrm{ml}$, significantly inhibited the appearance of SP in nasal secretions, which was increased by intranasal challenge with ovalbumin. Adiponectin also suppressed the development of nasal allergic-like symptoms, sneezing and rubbing behavior, when ovalbumin-sensitized mice were treated intranasally with adiponectin at more than $10.0 \mathrm{ng} / \mathrm{ml}$. The present results strongly suggested that adiponectin suppresses the production of SP and results in improvement of the clinical conditions of $A R$.

Allergic rhinitis (AR) is a chronic inflammatory response in nasal mucosa to several types of aeroallergens, with multiple symptoms of nasal obstruction, sneezing and rhinorrhea, among others. The mechanisms of chronic inflammation in AR is considered dependent on intense infiltration and activation of inflammatory cells such as mast cells and eosinophils, followed by secretion of a wide variety of chemical mediators and cytokines (1). Furthermore, although AR is not a life-threatening disease, clinical symptoms lead to inconvenience in daily life, sleep disorders, and low productivity, resulting in increased socioeconomical costs and lower quality of life $(1,2)$. The clinical conditions are primarily induced by chemical mediators secreted by polymorphonuclear cells, such as mast cells, basophils and eosinophils (1). In addition to the secretion of chemical mediators, these cells also release several types of cytokines and chemokines, which are responsible for the amplification and persistence of chronic inflammatory responses in nasal mucosa (1-3). There is also much evidence that nasal mucosa is innervated by sensory and autonomic nerves. After stimulation with aeroallergen, sensory nerves transmit signals generating sensations such as itching and motor 
reflexes, including sneezing (3-5). Antigenic stimulation of sensory nerves also causes an axonal reflex producing neuropeptides, especially substance $\mathrm{P}$ (SP), which are responsible for vasodilation, edema and activation of inflammatory cells in nasal mucosa (3-5).

Adipose tissue is considered an inert tissue mainly devoted to energy storage but is emerging as an active participant in regulating pathophysiologic processes, such as immunity and inflammation via the secretion of adipokines, including leptin, adiponectin and resistin, as well as cytokines and chemokines, such as tumor necrosis factor (TNF) $\alpha$, interleukin 6 and others $(6,7)$. Although the primary physiological function of adipokine is the regulation of metabolism, there is much evidence that adipokine plays essential roles in the development of allergic inflammation $(6,7)$. Leptin is reported to increase the proliferation of regulatory T-cells, and prevents the apoptosis of both T-cells and mature eosinophils $(7,8)$. Leptin is also able to stimulate the chemokinesis of eosinophils and increase the release of many types of inflammatory cytokines (8). On the other hand, adiponectin, the most prevalent adipokine secreted by adipose tissue, is considered an anti-inflammatory adipokine because it reduces the production of inflammatory cytokines and chemokines, including TNF $\alpha$ and IL6 (6). It is also reported that adiponectin inhibits the expression of endothelial adhesion molecules intercellular adhesion molecule 1 (ICAM1) and promotes the production of the anti-inflammatory cytokines IL10 and IL1 receptor antagonist $(6,7)$. In regard to the development of allergic diseases, exogenous administration of adiponectin attenuated the development of ovalbumin-induced airway hyper-responsiveness and airway inflammation by reducing inflammatory cells, especially eosinophils, infiltration and Th2 type cytokine appearance, which were increased by aerosolized ovalbumin challenge in mice (9). In human cases, the serum adiponectin levels in patients with AR was found to be much lower than that of healthy controls and positively correlated with the severity of AR (10). Although these reports strongly suggest that adiponectin plays essential roles in the development of AR, the precise mechanisms by which adiponectin favorably modifies the clinical conditions of AR are not well understood. The present study, therefore, was undertaken to examine the influence of adiponectin on the production of the neuropeptide, SP, which is an important mediator responsible for the development of clinical conditions of $\mathrm{AR}$ in vitro and in vivo.

\section{Materials and Methods}

Reagents. Recombinant mouse adiponectin was purchased from BioVender Laboratory Medicine Inc. (Modrice, Czech Republic) as a preservative-free pure powder. Ovalbumin, aluminum hydroxide and capsaicin were obtained from Wako Pure Chemicals Co., Ltd. (Osaka, Japan). Recombinant mouse nerve growth factor (NGF) was purchased from R \& D Systems Inc. ((Minneapolis, MN, USA) as a preservative-free pure powder.
Animals. Specific pathogen-free, male BALB/c mice, 6 weeks of age, were purchased from CLEA JAPAN Co., Ltd. (Tokyo, Japan). These animals were maintained in our animal facilities at $25 \pm 2^{\circ} \mathrm{C}$ with $55 \pm 10 \%$ humidity under a 12 -h light/dark cycle and were allowed free access to tap water and standard laboratory rodent chow (Oriental Yeast Co., Ltd., Tokyo, Japan) throughout the experiments. Each control and each experimental group consisted of five mice. All animal experiments were approved by the Ethics Committee for Animal Experiments of Showa University (Approval No. 05112).

Sensitization and challenge procedures. Mice were sensitized with ovalbumin according to a method described previously (11). Briefly, $1.0 \mu \mathrm{g}$ of ovalbumin with $1.0 \mathrm{mg}$ aluminum hydroxide was injected intraperitoneally into mice in a total volume of $1.0 \mathrm{ml}$ on 0,7 , and 14 days, followed by intranasal challenge with $25.0 \mathrm{mg} / \mathrm{ml}$ ovalbumin in a volume of $20.0 \mu \mathrm{l}$ on days 21,23 and 25 . After 7 days, different doses $(7.5$ to $200.0 \mathrm{ng} / \mathrm{ml})$ of adiponectin $(5.0 \mu \mathrm{l})$ were instilled bilaterally into the nasal vestibule $30 \mathrm{~min}$ before intranasal challenge with $0.1 \%$ ovalbumin in a volume of $5.0 \mu \mathrm{l}$. Control mice were treated by the same procedure with normal saline only.

Assessment for nasal symptoms. Nasal allergy-like symptoms were assessed by counting the numbers of sneezing and nasal rubbing movements for $10 \mathrm{~min}$ immediately after ovalbumin nasal challenge according to the methods described previously (12). The experimental mice were placed into a plastic animal cage $(35 \times 20 \times 30 \mathrm{~cm})$ for about $10 \mathrm{~min}$ for acclimation. After nasal instillation of $0.1 \%$ ovalbumin in a volume of $5.0 \mu \mathrm{l}$, mice were replaced in the plastic cage (one animal/cage) and the number of sneezes and nasal rubbing movements for 10 min were counted.

Preparation of nasal lavage fluids. Mice were killed by intraperitoneal injection with $100 \mathrm{mg} / \mathrm{kg}$ sodium pentobarbital (Kyoritsu Seiyaku Co., Ltd., Tokyo, Japan) 6 h after ovalbumin nasal challenge. The trachea was exposed and cannulated to introduce $1.0 \mathrm{ml}$ phosphate-buffered saline. The lavage fluid exiting the nares was collected and centrifuged at $1,000 \times g$ for $15 \mathrm{~min}$ at $4^{\circ} \mathrm{C}$. After measuring IgA by enzyme-linked immunosorbent assay (ELISA) (Bethyl Lab., Inc., Montgomery, TX, USA), the fluids were stored at $-40^{\circ} \mathrm{C}$ until use.

Cell culture. PC-12 cells (ATCC, Rockville, MD, USA), differentiate into sympathetic neuron-like cells, when they are stimulated with NGF. Cells at $1 \times 10^{4}$ cells $/ \mathrm{ml}$ (in a final volume of $2.0 \mathrm{ml}$ ) were added to 12 -well culture plates that contained different concentrations of adiponectin. After $2 \mathrm{~h}$, the cells were stimulated with $10.0 \mathrm{ng} / \mathrm{ml} \mathrm{NGF}$ (13). The cells were then examined under a phase-contrast microscope (model no. 1X70; Olympus Co., Ltd., Tokyo, Japan). The number of cells that had extended neurites was counted in 300 cells $24 \mathrm{~h}$ after culture (13). The number of neurites per cell was also recorded by actual counting $72 \mathrm{~h}$ after the start of culture. To prepare culture supernatants, PC-12 cells $\left(1 \times 10^{5}\right.$ cells/ml) were cultured with $10.0 \mathrm{ng} / \mathrm{ml} \mathrm{NGF}$ for $72 \mathrm{~h}$ in the presence of different concentrations of adiponectin and stimulated with $100.0 \mathrm{ng} / \mathrm{ml}$ capsaicin for $6 \mathrm{~h}$ (13). The culture supernatants were then collected, treated with $5 \%$ protease inhibitor to prevent spontaneous degradation of SP and stored at $-40^{\circ} \mathrm{C}$ until use.

Assay for SP. SP in nasal lavage fluids and culture supernatants were examined by commercially available ELISA test kits according to the manufacturer's recommendations. SP ELISA test kits were 


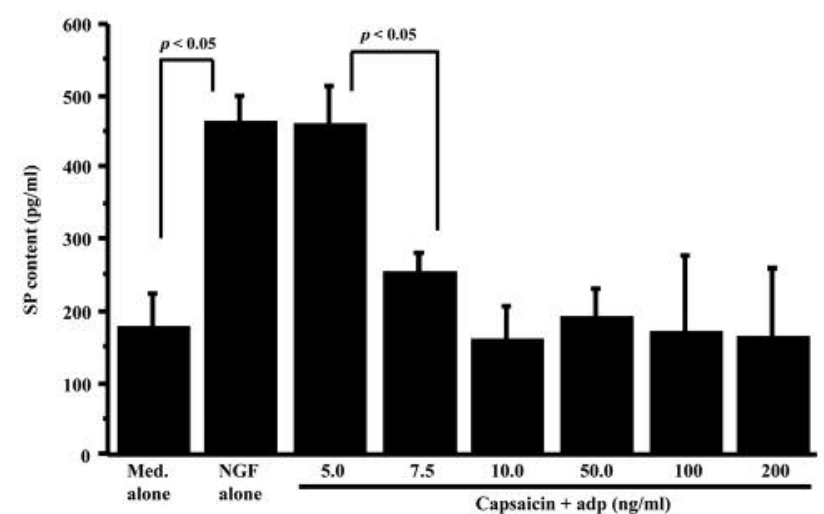

Figure 1. Influence of adiponectin (adp) on substance $P(S P)$ production from nerve growth factor $(N G F)$-treated $P C-12$ cells after capsaicin stimulation. PC-12 cells $\left(1 \times 10^{4}\right.$ cells $\left./ \mathrm{ml}\right)$ were treated with $10.0 \mathrm{ng} / \mathrm{ml}$ $N G F$ for $2 h$ and then stimulated with capsaicin in the presence of different concentrations of adp for $6 \mathrm{~h}$.SP levels in culture supernatants were examined by enzyme-linked immunosorbent assay. Data are expressed as the mean \pm standard error of the means of triplicate cultures. Med. alone: Medium alone.

obtained from ENZO Life Science Inc. (Farmingdale, NY, USA), and the minimum detectable levels of this kit was $8.04 \mathrm{pg} / \mathrm{ml}$.

Statistical analysis. Statistical analyses were performed with analysis of variance followed by Bonferroni correction. Values of $p<0.05$ were considered statistically significant.

\section{Results}

Influence of adiponectin on the function of PC-12 cells. The first set of experiments was undertaken to examine the influence of adiponectin on the function of PC-12 cells by assessment of the ability of cells to produce SP and neuron growth. We firstly examined the influence of adiponectin on capsaicin-induced SP production by PC-12 cells. As shown in Figure 1, although treatment of cells with adiponectin at $5.0 \mathrm{ng} / \mathrm{ml}$ did not affect the production of SP by PC-12 cells compared with cells pretreated with NGF alone, adiponectin at $7.5 \mathrm{ng} / \mathrm{ml}$ and more significantly inhibited the ability of cells to produce SP, which was increased by capsaicin stimulation. We then examined the influence of adiponectin on neuron growth from PC-12 cells. As shown in Figure 2, adiponectin did not exert significant effects on neuron growth from PC-12 cells induced by NGF stimulation: the number of cells with neurites and neurites per cells were nearly identical to those observed in control cultures (NGF alone).

Influence of adiponectin on the development of ovalbumininduced nasal allergy-like symptoms. The second set of experiments was undertaken to examine whether intranasal administration of adiponectin into ovalbumin-sensitized mice affected the development of nasal allergy-like symptoms induced by nasal antigenic challenge. Nasal symptoms were assessed by counting the numbers of sneezes and nasal rubbing movements for $10 \mathrm{~min}$ immediately after ovalbumin nasal challenge. As shown in Figure 3A, treatment of ovalbuminsensitized mice with adiponectin at $5.0 \mu \mathrm{g}$ did not suppress the development of sneezing induced by ovalbumin provocation. However, intranasal administration of adiponectin at $10.0 \mu \mathrm{g}$ and more inhibited the development of sneezing (Figure 3A). We then examined the influence of adiponectin on nasal rubbing movements induced by ovalbumin nasal challenge. As shown in Figure 3B, intranasal administration of adiponectin at $10.0 \mu \mathrm{g}$ and more significantly suppressed the development of nasal rubbing movements and the number of movements were much lower than that observed in ovalbumin-sensitized, non-treated mice $(p<0.05)$.

Influence of adiponectin on SP appearance in nasal lavage fluids obtained from ovalbumin-sensitized rats. The third set of experiments was undertaken to examine the influence of adiponectin on the appearance of SP in nasal lavage fluids obtained from sensitized mice after ovalbumin nasal challenge. To do this, ovalbumin-sensitized mice were intranasally administered various doses of adiponectin before ovalbumin challenge. Nasal lavage fluids were obtained from rats $6 \mathrm{~h}$ after challenge and SP levels were examined by ELISA. As shown in Figure 4, intranasal administration of adiponectin at $10.0 \mu \mathrm{g}$ and more significantly inhibited increase in SP levels in nasal lavage fluids, which was increased by intranasal challenge with ovalbumin.

\section{Discussion}

Adiponectin, a protein produced by adipose tissue and classified into the adipokine family, is reported to play a pivotal role in the development of allergic diseases, including AR, through modulation of inflammatory cytokine production and the expression of some adhesion molecules (6-10). Although there is much evidence that neuropeptides, such as SP, calcitonin gene-related peptides and vasoactive intestinal peptide, are implicated as active participants in the development of allergic inflammatory responses (3-5), the influence of adiponectin on neuropeptide production is not well defined. The present study, therefore, was undertaken to examine the influence of adiponectin on the production of neuropeptide through the choice of SP in vitro and in vivo.

The present results clearly showed that adiponectin at $7.5 \mathrm{ng} / \mathrm{ml}$ and more exerted suppressive effects on SP production from PC-12 cells induced by capsaicin stimulation without lethal effects on neurons. SP is widely distributed in the central and peripheral nervous systems. In the central nervous system, SP is thought to participate in various 

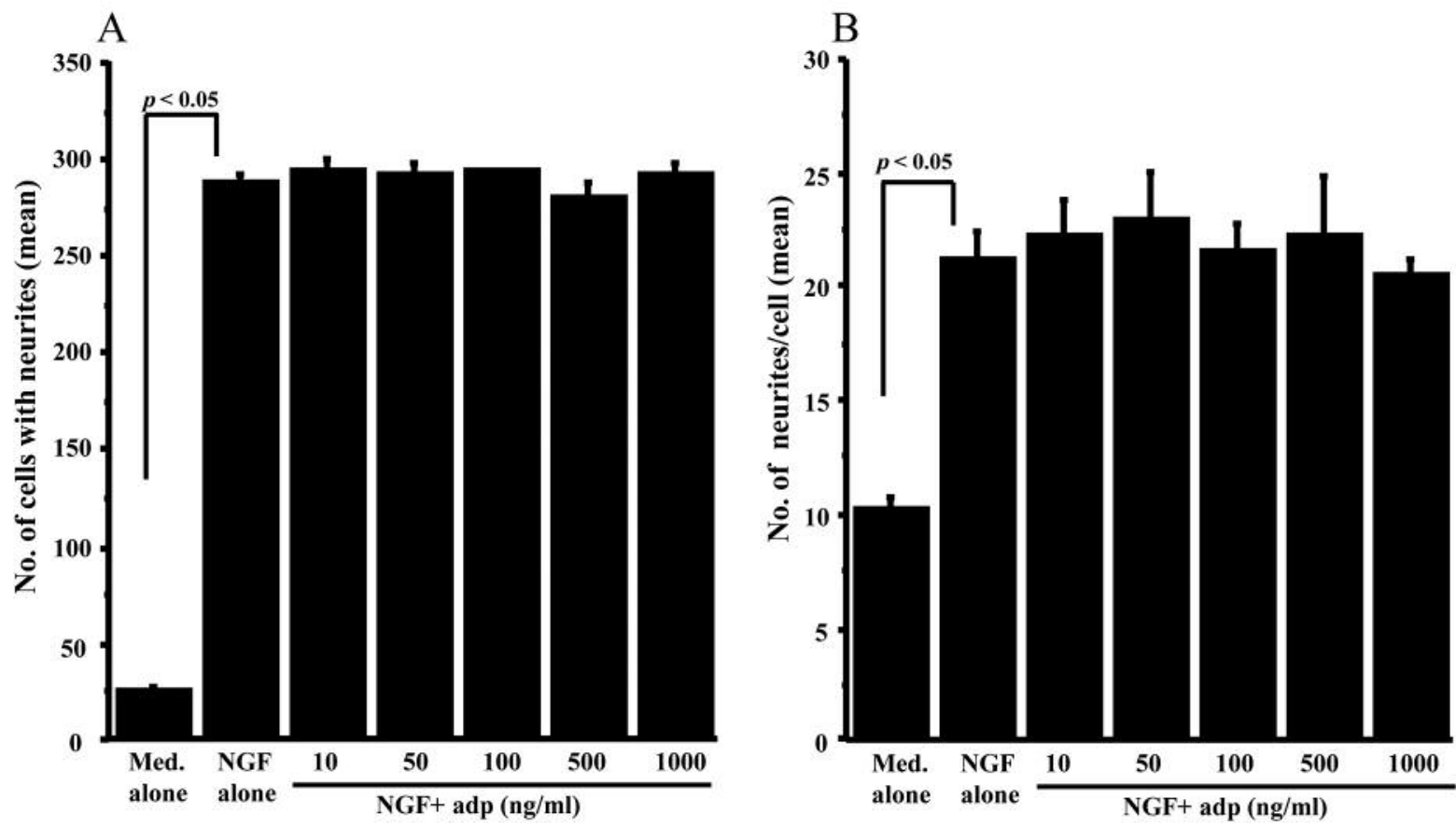

Figure 2. Influence of adiponectin (adp) on neurite outgrowth (A) and the number of neurites (B) produced by PC-12 cells in vitro. PC-12 cells $\left(1 \times 10^{4} \mathrm{cells} / \mathrm{ml}\right)$ were treated with $10.0 \mathrm{ng} / \mathrm{ml}$ nerve growth factor $(\mathrm{NGF})$ in the presence or absence of different concentrations of adp. The number of cells extended neurites was counted $24 \mathrm{~h}$ after culture. The number of neurites per cell was also recorded $72 \mathrm{~h}$ after the start of culture. The data are expressed as the mean \pm standard error of the means of triplicate cultures. Med. alone: Medium alone.
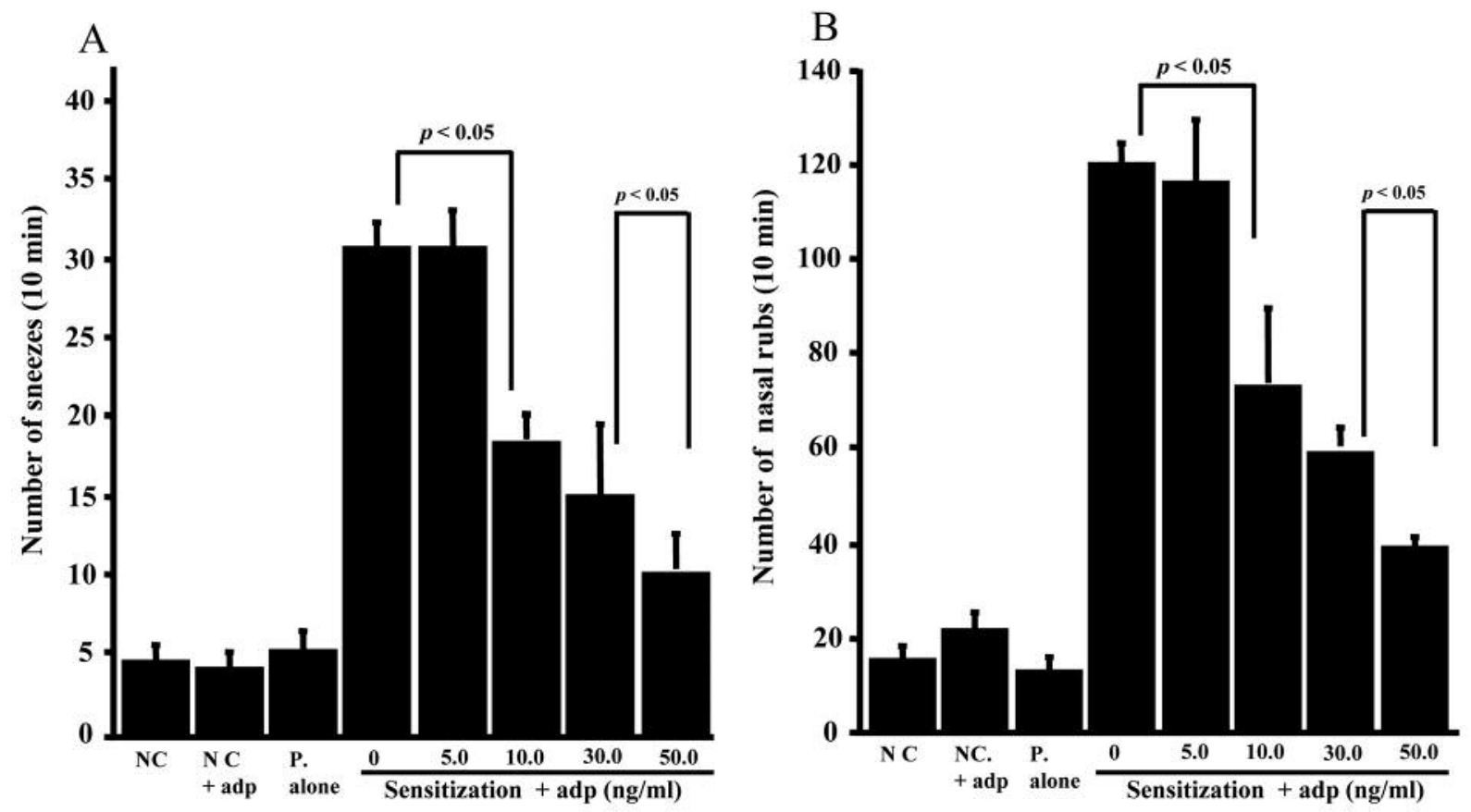

Figure 3. Influence of adiponectin (adp) on the development of nasal allergy-like symptoms induced by nasal ovalbumin instillation in sensitized mice. Ovalbumin-sensitized mice were treated intranasally with different concentrations of adp. The number of sneezes $(A)$ and nasal rubs $(B)$ were counted for 10 min immediately after ovalbumin nasal challenge. Data are expressed as the mean \pm standard errors of the mean of five mice. NC: Non-sensitized control; P. alone: primary sensitization alone. 


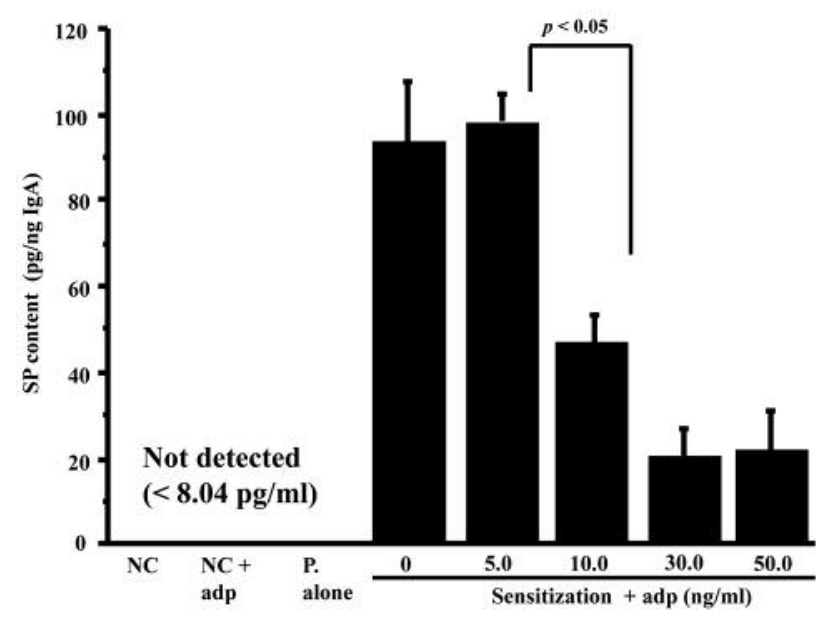

Figure 4. Influence of adiponectin ( $a d p)$ on the appearance of substance $P(S P)$ in nasal lavage fluids after nasal ovalbumin instillation in sensitized mice. Ovalbumin-sensitized mice were treated intranasally with different doses of adp. The levels of SP in nasal lavage fluids obtained from mice $6 \mathrm{~h}$ after ovalbumin nasal challenge were measured by enzyme-linked immunosorbent assay. The data are expressed as the mean \pm standard error of the mean of five mice. NC: Non-treated control; P. alone: primary sensitization alone.

behavioral responses and neurotransmission of pain and noxious stimuli, and modulates autonomic reflexes in the spinal cord (14). In the peripheral nervous system, SP is localized in the sensory nerves and released after axonal reflex, leading to vasodilation, plasma extravasation and mast cell degranulation $(3-5,14)$. SP is also reported to increase inflammatory cell activation and the production of inflammatory cytokines and chemical mediators, including histamine (14). Intranasal application of SP induces nasal symptoms, such as nasal itching and sneezing in healthy humans (15). Administration of SP into the nasal cavity of AR model animals has been reported to increase both mRNA expression of chemokine (C-C motif) ligand 5 (RANTES) in the nasal mucosa and the number of eosinophils in nasal lavage fluids (16). Taken together with these reports, the present results may be interpreted to show that adiponectin inhibits the development of nasal allergic inflammation through suppression of SP production by neurons and results in attenuation of the development of clinical conditions of AR.

The second set of experiments was undertaken to examine whether intranasal application of adiponectin could inhibit allergen-induced SP production and result in attenuation of the development of nasal allergy-like symptoms using a mouse model of AR. The present results clearly showed that intranasal application of adiponectin at $10.0 \mathrm{ng} / \mathrm{ml}$ and more into ovalbumin-sensitized mice inhibited the development of nasal allergy-like symptoms, such as sneezes and nasal rubbing movements, through the suppression of SP in the nasal cavity, which are increased by nasal antigenic stimulation. SP increases mast cell degranulation to produce chemical mediators responsible for development of the earlyphase allergic response characterized by sneezing and nasal itching $(5,17)$. SP also activates macrophages to produce pro-inflammatory cytokines, including IL1 $\beta$, IL6 and TNF $\alpha$, which function as additional stimuli of allergic inflammation $(18,19)$. Furthermore, SP increases the ability of sensory nerves and nasal epithelial cells to produce NGF $(20,21)$, which contributes to amplifying the early-phase allergic response through the promotion of both survival and degranulation of mast cells $(5,21)$.

Although the present results strongly suggest that adiponectin attenuates nasal allergy-like symptoms through the suppression of SP release after antigenic challenge, the precise mechanisms by which adiponectin inhibits SP production from sensory nerves after antigenic challenge are unknown. Activation of the extracellular signal-regulated kinase $1 / 2$ (ERK1/2) pathway is reported to be essential for the production of both SP in dorsal root ganglions and peripheral nerve fibers (22). Activation of ERK1/2 and nuclear factor-kB (NF-kB) pathways is also reported to increase SP production and is responsible for the development of neurogenic inflammation (22, 23). Adiponectin exerted the suppressive effects on the phosphorylation of ERK1/2 and IkB degradation and subsequent NF-kB activation $(24,25)$. Together with these reports, there is a possibility that adiponectin inhibits the phosphorylation of ERK $1 / 2$ and IKB activation, and results in suppression of both SP production and the development of nasal allergic symptoms induced by antigenic stimulation.

\section{Conflicts of Interest}

The Authors declare that there is no conflict of interests regarding the publication of this article.

\section{References}

1 Pawankar R, Mori S, Ozu C and Kimura S: Overview on the pathomechanisms of AR. Asian Pacific Allergy 1: 157-167, 2011.

2 Ramirez-Jimenez F, Pavon-Romero G, Juarez-Martinez LL and Teran LM: Allergic Rhinitis. J Aller Ther S5: 006, 2012.

3 Pfaar O, Raap U, Holz M, Hormann $\mathrm{K}$ and Klimek L: Pathophysiology of itching and sneezing in allergic rhinitis. Swiss Med Wkly 139: 35-40, 2009.

4 Schaper C, Gustavus B, Koch B, Ewert R, Felix SB, Kunkel G, Noga O, Glaser S: Effect of fluticasone on neuropeptides in nasal lavage in persistent allergic rhinitis. J Invest Allergol Clin Immunol 20: 214-221, 2010.

5 McDonald JL, Cripps AW, Smith PK, Smith CA, Xue CC and Golianu B: The anti-inflammatory effects of acupuncture and their relevance to allergic rhinitis: A narrative review and proposed model. Evidence-Based Com Alter Med 2013: 591796, 2013. 
6 Fantuzzi G: Adipose tissue, adipokines, and inflammation. J Allergy Clin Immunol 115: 911-919, 2005.

7 Ciprandi G, Caimmi D, Raschetti R, Miraglia Del Giudice M, Salpietro C, Caimmis S and Castellazzi AM: Adipokines and their role in allergy. Int J Immunopathol Pharmacol 24: 13-16, 2011.

8 Radon K, Schulze A, Schierl R, Dietrich-Gumperlein G, Nowak $\mathrm{D}$ and Jorres RA: Serum leptin and adiponectin levels and their association with allergic sensitization. Allergy 63: 1448-1454, 2008.

9 Shore SA, Terry RD, Flynt L, Xu A and Hung C: Adiponectin attenuates allergen-induced airway inflammation and hyperresponsiveness in mice. J Allergy Clin Immunol 118: 389-395, 2006.

10 Hsueh KC, Lin YJ, Lin HC and Lin CY: Serum leptin and adiponectin levels correlate with severity of allergic rhinitis. Pediatr Allergy Imunol 21: e155-e159, 2010.

11 Jung D, Lee S and Hong S: Effects of acupuncture and moxibustion in a mouse model of allergic rhinitis. Otolaryngol Head Neck Surge 146: 19-25, 2011.

12 Kashiwabara M, Asano K, Mizuyoshi T and Kobayashi H: Suppression of neuropeptide production by quercetin in allergic rhinitis model rats. BMC Com Alter Med 16: 132, 2016.

13 Toyoda M, Nakamura M, Nakada K, Iida M, Nakamura M, Otani M, Etoh T, Nakagawa $\mathrm{H}$ and Morohashi M: Effect of epinastine hydrochloride, a second-generation histamine $\mathrm{H} 1$ receptor antagonist, on sensory neurons in vitro. Allergol Int 54: 565-572, 2005.

14 O'connor TM, O'connell J, O'brien DI, Goode T, Bredin CP and Shanahan F: The role of substance $\mathrm{P}$ in inflammatory disease. J Cell Physiol 201: 167-180, 2004.

15 Abu-Bakra M and Jones NS: Does stimulation of nasal mucosa cause referred pain to the face? Clin Otolaryngol Allied Sci 26: 430-432, 2001.

16 Zhang R, Liu G, Wen W, Yan Z and Wu G: The significance and effect of substance $\mathrm{P}$ on the expression of RANTES mRNA in allergic rhinitis. Lin Chuang Er Bi Yan Hou Ke Za Zhi 20: $73-$ 77, 2006.

17 Kaise T, Akamatsu Y, Ikemura T, Ohmori K, Ishii A and Karasawa A: Involvement of neuropeptides in the allergic nasal obstruction in guinea pigs. Jpn J Pharmacol 86: 196-202, 2001.

$18 \mathrm{Renz} \mathrm{H}$ : The role of neurotrophins in bronchial asthma. Eur J Pharmacol 429: 231-237, 2001
19 Cuesta MC, Quintero L, Pons H and Suarez-Roca H: Substance $\mathrm{P}$ and calcitonin gene-related peptides increase IL-1 $\beta$, IL-6 and TNF- $\alpha$ secretion from human peripheral blood mononuclear cells. Neurochem Int 40: 301-306, 2002.

20 Skoff AM and Adler JE: Nerve growth factor regulates substance $\mathrm{P}$ in adult sensory neurons through both TRKA and p75 receptors. Exp Neurology 197: 430-436, 2006.

21 Nockher WA and Renz H: Neurotrophins and asthma: Novel insight into neuroimmune interaction. J Allergy Clin Immunol 117: 67-71, 2006.

22 Kondo T, Oshima T, Koseki J, Hattori T, Kase Y, Tomita T, Fukui $\mathrm{H}$, Watari J and Miwa $\mathrm{H}$ : Effect of rikkunshitou on the expression of substance $\mathrm{P}$ and CGRP in dorsal root ganglion neurons and voluntary movement in rats with experimental reflux esophagitis. Neurogastroentol Motil 26: 913-921, 2014.

23 Ang SF, Moochhala SM, MacAry PA and Bhatia M: Hydrogen sulfide and neurogenic inflammation in polymicrobial sepsis: Involvement of substance P and ERK-NF-kappaB signaling. Plos One 6(9): e24535, 2011

24 Park PH, Huang H, McMullen MR, Mandal P, Sun L and Nagy LE: Suppression of lipopolysaccharide-stimulated tumor necrosis factor- $\alpha$ production by adiponectin is mediated by transcriptional and post-transcriptional mechanisms. J Biol Chem 283: 2685026858, 2008.

25 Motobayashi Y, Izawa-Ishizawa Y, Ishizawa K, Orino S, Yamaguchi K, Kawazoe K, Hamano S, Tsuchiya K, Tomino S and Tamaki T: Adiponectin inhibits insulin-like growth factor-1induced cell migration by suppression of extracellular signalregulated kinase $1 / 2$ activation, but not AKT in vascular smooth muscle cells. Hypertension Res 32: 188-193, 2009.
Received October 18, 2018

Revised November 5, 2018

Accepted November 6, 2018 